same hæmolytic streptococci can give rise to various manifestations in a single community. At Queen Charlotte's Hospital in London, this typing method has provided the valuable information that, in puerperal fever, infection of the placenta by organisms in the genital passages at the beginning of labour is almòst a negligible cause of puerperal fever ; the important sources of infection are the attendants or other contacts, or even the upper respiratory passages of the mother herself. Similar work on the staphylococci has not yet given such striking results, but it is proceeding. The War has, of course, greatly stimulated work on organisms of the gas-gangrene group. Methods of growing anaerobic bacteria in the presence of air have been devised, and they have been grown on ordinary broth or peptone water containing a small strip of sheet iron.

\section{A Film of Hospital Treatment}

A Remarkable film, made by Gaumont Instructional Films, which is being shown under the auspices of the British Council, shows the successful operation by a British surgeon for the removal of the whole lung. The pictures are so taken that the spectator sees at least as much as, if not more than, most of the surgeon's assistants. At the beginning of the film the patient is shown, with his fellow workers in a factory, undergoing routine examination of the chest by X-ray. A cancer of the root of the lung is suspected in him, and the diagnosis is discussed by several experts in the light of subsequent examinations. Operation is decided upon and the patient sees the hospital almoner, who relieves his anxiety about the welfare of his wife and family while he is away from work. The special methods of anæsthetizing the patient are then shown and the operation itself follows, the spectator seeing the beating heart, the ligature and division of the pulmonary veins and the bronchus and other details. The rest of the film shows the after-care of the patient and his rehabilitation in a convalescent home until he returns to work. The British Council's chief function is, of course, to make British institutions and methods known abroad. This film, however, might well be shown widely in Great Britain.

\section{Women's Health in War-time}

Is a note entitled "Healthier Women--a War-time Asset", the Statistical Bulletin states that comparison of the mortality of women in the United states for the two years prior to the entry of that country into the War of 1914-18 with that for the two years (1940-41) before Pearl Harbour shows that women were benefited by the increasing control over disease. During this 25-year period, the death-rate among women insured in the Industrial Department of the Metropolitan Life Insurance Company, New York, has been reduced by about half. There were thirteen deaths in every 1,000 women aged from 15 to 74 in 1915-16 as compared with only seven in 1940-41. The decline in mortality from tuberculosis has contributed more than any other factor to this remarkable record. The control of pneumonia has also contributed much to the improvement in the total mortality among women. Diseases associated with pregnancy and childbirth have been sharply reduced since 1918. Diabetes alone has increased in the past twenty-five years among women. As regards suicide, the death-rate among insured women in 1940-41 was about two thirds the rate in 1915-16, and for accidents the proportion was three fourths.

\section{An Ultra-High-Speed Motion-Picture Camera}

According to an article by H. J. Smith (Bell Lab. Rec., 22, No. 1 ; October 1943) a new high-speed camera, known as the Western Electric Fastax HighSpeed Motion-Picture Camera, is capable of taking pictures at the rate of 8,000 per second. Fastax cameras are made in both $8 \mathrm{~mm}$. and $16 \mathrm{~mm}$. models. The $8 \mathrm{~mm}$. model will take from 300 to 8,000 pictures per second, depending on the voltage applied to the motors, while the $16 \mathrm{~mm}$. model will take from 150 to 4,000 pictures per second. Approximately full speed is obtained at nominal line voltages from 110 to 125 volts. To secure lower speeds a rheostat may be placed in series with the motor to reduce the applied voltage.

These new cameras are of the continuous-motion type employing an optical compensator, or rotating prism, between the lens and the sprocket. The $8 \mathrm{~mm}$. camera has an eight-sided prism permitting eight pictures per prism revolution, and the $16 \mathrm{~mm}$. camera has a four-sided prism permitting four pictures per prism revolution; each revolves in synchronism with the film. The prism creates successive and properly spaced images travelling with the film. The image gathered by the lens is refracted by the prism upward to meet the incoming frame, and as the frame advances downward, the image follows, thereby permitting continued exposure throughout the period that the film travels past the aperture. The duration of the exposure is controlled by the speed of rotation of the prism. Both these cameras are arranged to use either 100-ft. or 50-ft. spools of film. At top speed the film travels through the camera at about 70 miles per hour, the exposure time per frame being about $1 / 30,000$ sec. for the $8 \mathrm{~mm}$. camera and $1 / 12,000 \mathrm{sec}$. for the $16 \mathrm{~mm}$. camera. At full voltage one hundred feet of film runs through the camera in approximately $1 \cdot 25$ sec. The motor driving mechanism is described in the article.

\section{Physical Significance of Maxwell's Theory}

Is a lecture delivered by Mario Bunge on June 2], 1943, before the Faculty of Industrial and Agricultural Chemistry of the National University of Litoral, under the title "Significado Fisico e Historico De La Teoria. De Maxwell", the work of Maxwell is considered, and its influence in his own day and also on posterity is dealt with (Buenos Aires : Universidad Obrera Argentina. Pp. 16). Among the important effects of Maxwell's theory may be noted the downfall of mechanism for the second time in history. The first non-mechanical theory was the undulatory theory of light under Huygens, Fresnel, MacCullagh, Green, Cauchy, etc., and now for the second time physics seemed to be released from the thraldom of mechanism. The opinion of Gustavo Avé Lallemant, one of the few authorities on physical science in the days of Maxwell, is worth recording. He said that the English, so practical, had ereated a new science, "Ia Electrometria", which teaches us how to calculate all the effects of electrical phenomena, though adding nothing to the manner of explaining the nature of electricity (Anales de la Sociedad Cientifica Argentina, 13,193 ; 1882). For Maxwell a model was simply a method for teaching but not a real need, and he was convinced that electromagnetism was not reducible to mechanism. In conclusion, it is pointed out that Maxwell's theory has developed in its form and consequences in such a manner, that in the mechanics of de Broglie, Schrödinger, Heisenberg, Born and 
Dirac, not only has there been a unification in electromagnetism and optics, but these have also been unified with mechanics. The evolution of physics has therefore followed, to a considerable extent, the pathway marked out by Faraday and Maxwell.

\section{Riboflavin Deficiency in Fowls}

DEFrCIENCY of riboflavin (vitamin $\mathrm{B}_{2}$ ) in chick rations leads to poor growth and may give rise to 'curled toe paralysis'. Where skim milk is available, this trouble is unlikely to occur; but under war-time conditions rearers are forced to depend chiefly on mashes. Official regulations have ensured that all rearing mixtures contain adequate riboflavin; but owing to the fact that essential ingredients such as dried skim milk and dried yeast are in short supply, the possibility of using an alternative source of the vitamin has been investigated by the Chemical Division of the. Agricultural Research Institute of Northern Ireland. The results are published in its sixteenth Annual Report, 1942-43. Chicks were reared from hatching to fourtoen days on a basal ration adequate in protein, minerals, and vitamins $A$ and $D$ but deficient in riboflavin.. They were then divided into groups and supplied with various levels of either dried skim milk or dried liver in addition to their basal ration, one group continuing on the basal ration alone. 5 per cent dried liver was slightly more effective than 10 per cent dried skim milk for growth, and no cases of 'curled toe paralysis' occurred in either group. So little as 1 per cent dried liver improved growth but was insufficient to prevent the leg weakness. A further test fully confirmed these results and also showed that 10 per cent dried lung was as good as 5 per cent dried liver, so that both meals may prove a valuable new source of riboflavin-rich protein supplement for chick-rearing rations. A small stock of these meals has been produced, and work on the subject is being continued.

\section{Literature of Rheology}

In the August issue of the Rheology Bulletin, published by the Society of Rheology under the auspices of the American Institute of Physics, a new feature, "Rheology Reviews", is started with a survey by Dr. R. Dow of "Some Rheological Properties of Matter under High Hydrostatic Pressure". It is intended that the new series shall furnish a perspective of a wide field of knowledge, and that each survey shall be prepared by an expert in the field. In the same number more than twenty pages of abstracts are given. The journal is published quarterly from 175 Fifth Avenue, New York, N.Y., and was founded to help workers in the fields of elasticity, viscosity, plasticity and the like, to a better understanding of their common problems. It was created as a medium for the exchange of information as to theories and methods relating to the rheological properties of matter. The issue for November 1942 contains details of the contents of the Journal of Rheology published by the Society during 1929-33. In 1933 the new journal Physics, now called the Journal of Applied Physics, began to publish the rheological material. Incidentally, the Bulletin illustrates a cheaper method of publication of journals with a small circulation : the matter is prepared on a typewriter with graphs and the mathematical parts added by hand. The copies are then printed by the ase of photo-lithography.

\section{Electrolytic Production of Hydrogen and Oxygen}

"The Production of Hydrogen and Oxygen by the Electrolysis of Water" is the subject of a paper (J. Inst. Elec. Eng., 90, Pt. 1, No. 35 ; Nov. 1943) by Mr. C. E. Bowen, which, reviews the principles and practice of the electrolysis of water and discusses its interest to the electrical engineer. Following the chemical expression of the process, the various factors influencing the yields and power requirements are considered. In the theoretical treatment, the application of Faraday's law is discussed, together with the question of current efficiency. The factors controlling the cell voltage, such as minimum-decomposition voltage, over-voltage, current density and resistance of electrolytes are studied, data being supplied as a guide to the general design requirements of this type of equipment. Methods and materials of construction are also discussed, with some notes on the handling of the gases. The paper describes some modern types of apparatus, and the performance of the equipment is illustrated. The demand for the two gases is discussed and some of their uses are defined. Finally, the author suggests, on the basis of some of the figures included, that the large amounts of power concerned should be of the greatest interest to electrical engineers.

\section{Anti-malaria Campaign in Panama}

A RECENT paper (Bol. Of. San. Panamericana, 22, 502 ; 1943) published by the Malaria Section of the Ministry of Public Health and Public Works of Panama contains an account of the following means adopted against malaria in Panama. More than 300 Anopheles breeding places in the towns of the interior are regularly kept under control by weekly inspection and identification of the larvæ. Eight. species of Anopheles have been identified, namely, A. albimanus, argyritarsis, pseudopunctipennis, apicimacula, albitarsis, strodei and neomaculipalpus. The methods most favoured include the use of oil and Paris green. Paris green, which destroys only the larvæ, is preferred owing to the economy in use and facility of transportation. An approximate idea of the incidence of malaria in the different regions can be obtained from the incidence of malaria mosquitoes and the splenic enlargement and parasitic determination in school children. Rainfall records in infested regions are also of help. Sanitary education by lectures, cinemas, meetings, etc., is slowly progressing.

\section{Treatment of Peripheral Nerve Injuries}

The British Medical Bulletin is published monthly by the British Council for distribution abroad. Each number contains, in addition to valuable summaries of British research papers of medical interest, a special summary of recent work in some field of inquiry, which is written by an authority on that subject. Prof. H. J. Seddon, in an issue devoted to peripheral nerves, writes upon peripheral nerve injuries (Brit. Med. Bull., 1, No. $7 ;$ 1943). Clinical problems presented by nerve injuries have not, he says, received great attention except during times of war, when injuries of peripheral nerves are commoner than they are in normal times. The increasing mechanization of our civilization may, however, result in an increase of peripheral nerve injuries even in times of peace. In 1940 the Ministry of Health and the Medical Research Council established, at civilian hospitals in the Emergency Medical Service, 